\title{
Rapid and Non-Destructive Monitoring of Moisture Content in Livestock Feed Using a Global Hyperspectral Model
}

\author{
Daniel Dooyum Uyeh ${ }^{1,2,3}$, Juntae Kim ${ }^{4}\left(\mathbb{D}\right.$, Santosh Lohumi ${ }^{4}$, Tusan Park ${ }^{1,3, * \mathbb{C}}$, Byoung-Kwan Cho ${ }^{4, *(\mathbb{D})}$, \\ Seungmin Woo ${ }^{1,2,3}$, Won Suk Lee ${ }^{5}\left(\right.$ ) and Yushin $\mathrm{Ha}^{1,2,3, *}$ \\ 1 Department of Bio-Industrial Machinery Engineering, Kyungpook National University, Daegu 41566, Korea; \\ uyehdooyum@gmail.com (D.D.U.); woosm7571@gmail.com (S.W.) \\ 2 Upland-Field Machinery Research Centre, Kyungpook National University, Daegu 41566, Korea \\ 3 Smart Agriculture Innovation Center, Kyungpook National University, Daegu 41566, Korea \\ 4 Department of Biosystems Machinery Engineering, College of Agricultural and Life Science, \\ Chungnam National University, 99 Daehak-ro, Yuseong-gu, Daejeon 34134, Korea; biosch94@gmail.com (J.K.); \\ Santosh.sanny123@gmail.com (S.L.) \\ 5 Department of Agricultural \& Biological Engineering, University of Florida, Gainesville, FL 32611, USA; \\ wslee@ufl.edu \\ * Correspondence: tusan.park@knu.ac.kr (T.P.); chobk@cnu.ac.kr (B.-K.C.); yushin72@knu.ac.kr (Y.H.)
}

check for updates

Citation: Uyeh, D.D.; Kim, J.; Lohumi, S.; Park, T.; Cho, B.-K.; Woo,

S.; Lee, W.S.; Ha, Y. Rapid and

Non-Destructive Monitoring of

Moisture Content in Livestock Feed Using a Global Hyperspectral Model. Animals 2021, 11, 1299. https:// doi.org/10.3390/ani11051299

Academic Editors: Mélissa Duplessis and Liliana Fadul-Pacheco

Received: 22 March 2021

Accepted: 28 April 2021

Published: 30 April 2021

Publisher's Note: MDPI stays neutral with regard to jurisdictional claims in published maps and institutional affiliations.

Copyright: (c) 2021 by the authors. Licensee MDPI, Basel, Switzerland. This article is an open access article distributed under the terms and conditions of the Creative Commons Attribution (CC BY) license (https:/ / creativecommons.org/licenses/by/ $4.0 /)$.
Simple Summary: Moisture content is an important parameter for monitoring the quality of feed and feed materials as its established ranges serve as markers for safe storage, mixing, and feeding animals. The moisture content of feed materials changes very rapidly and necessitates rapid measurement. Current moisture content measurement methods are time-consuming, destructive, and require specialized skills. This often causes reduced and/or delayed testing, which results in the spoilage of feed and feed materials. Additionally, the improper balance of dry matter intake which is inversely proportional to moisture content often causes metabolic diseases for animals consuming the diet. To solve these, we have developed a rapid and non-destructive global hyperspectral model that could quantify moisture content in feed materials. Our results show that the developed model is robust, could provide a method to measure the distribution of moisture in feed, and has potential for implementation in a commercial setting.

Abstract: The dry matter (DM) content of feed is vital in cattle nutrition and is inversely correlated with moisture content. The established ranges of moisture content serve as a marker for factors such as safe storage limit and DM intake. Rapid changes in moisture content necessitate rapid measurements. A rapid and non-destructive global model for the measurement of moisture content in total mixed ration feed and feed materials was developed. To achieve this, we varied and measured the moisture content in the feed and feed materials using standard methods and captured their images using a hyperspectral imaging (HSI) system in the spectral range of 1000-2500 $\mathrm{nm}$. The spectral data from the samples were extracted and preprocessed using seven techniques and were used to develop a global model using partial least squares regression (PLSR) analysis. The range preprocessing technique had the best prediction accuracy $\left(R^{2}=0.98\right)$ and standard error of prediction $(2.59 \%)$. Furthermore, the visual assessment of distribution in moisture content made possible by the generated PLSR-based moisture content mapped images could facilitate precise formulation. These applications of HSI, when used in commercial feed production, could help prevent feed spoilage and resultant health complications as well as underperformance of the animals from improper DM intake.

Keywords: dairy cattle; dry matter intake; feed materials; metabolic diseases; multivariate analyses; precision feed formulation; rapid and non-destructive measurement; safe storage; total mixed ration

\section{Introduction}

Moisture content is an important and widely used indicator in the processing and testing of foods. The terms moisture content and water content have been used interchange- 
ably to designate the amount of water in a product. Since the dry matter in food is inversely related to the moisture it contains, the moisture content is of direct economic importance to the processor and the consumer. Grain that contains excess water is subject to rapid deterioration from bacteria, mold growth, heating, insect damage, and sprouting [1]. In the livestock industry, moisture content of feed materials, and total mixed ration (TMR) for cattle is very important in preventing spoilage [2] and ensuring good health of the animal. In most countries, TMRs are mixed on the farm. However, in some countries such as the Republic of Korea, TMR feed is manufactured in factories, bagged, stored, and sold to farms [2]. This is because most of the raw materials for feed production are sourced internationally, which makes it difficult for small farmers (less than 50 cattle) [3] to import, store, and process by themselves. The amount of water in the TMR feed and feed materials can also be a factor to cause bacterial and fungal spoilage of feed when the temperature is conducive [4]. However, microbial spoilage could occur in environments with low moisture content at conducive temperatures [5]. In [6], the microbial activity of selected feed materials was monitored at nine different moisture contents. In that study, they established critical moisture contents between $16-46 \%$ to be favorable for microbial growth to occur depending on the microorganism and material.

DMI is a factor that must be estimated before an animal's diet can be properly formulated. Routine monitoring of the dry matter content of feed ingredients is an important strategy in preparing TMR for dairy cattle [7].

Estimating the moisture content could also help mitigate issues of sorting TMR feed by dairy cattle. Sorting is part of the problems associated with feeding TMR to dairy cattle. To solve the problem of sorting that could cause subacute ruminal acidosis, the addition of water to dry TMR is conventionally considered to be a beneficial management practice. It has been demonstrated that reducing TMR dry matter concentration from 80 to $64 \%$ [8] results in a reduction in the extent of feed sorting against long particles and in favor of short particles, a tendency for increased Neutral Detergent Fiber intake, and higher fat content in the produced milk (3.41 vs. 3.31\%) [8]. However, reducing the dry matter concentration from 57.6 to $47.9 \%$ [9] encouraged greater feed sorting and reduced DMI in TMR containing primarily forage sources. Rapid measurement of moisture content would help guide the grower to control the right amount of water content in the TMR that would prevent sorting.

Currently, there are well-developed and commercialized non-destructive thermal sensors. In [10], thermal imaging in agriculture was reviewed. Various specifications of operational thermal sensors were provided. This study showed a wide range of thermal imaging methods that can be used in measuring the temperature of the feed or feed materials non-destructively and rapidly. However, in moisture content, the available measurement methods include the use of a capacitance sensor for nuts and grains moisture quantification [11] and a miniaturized non-destructive microwave sensor for measuring the moisture content measurement of chickpea [12]. Furthermore, the near-infrared technique has been widely applied for estimating water stress in crops [13], feed materials [14], and in grains [15]. Additionally, change in the weight of materials before and after drying using hot air ovens, microwaves, etc., is currently used for determining moisture content [16].

Additionally, with the considerable physical and chemical variations in the materials used for formulating feeds, multiple non-destructive sensors would be needed to measure each material. The above moisture content measurement methods of animal feed including the conventional drying technique in a hot air oven are time-consuming and destructive. The time-consuming factor could set back livestock feed production, as the materials are also susceptible to rapid change, usually occurring before the results from the current methods have been established.

Spectroscopic methods such as mid-infrared spectroscopy (MIRS), near-infrared spectroscopy (NIRS), and Raman spectroscopy have the advantages of being rapid and nondestructive [17]. Near-infrared hyperspectral imaging [18] combines two-dimensional object visualization obtained by spectral imaging and has the potential of effectively describing constituent distribution in a sample with each pixel containing spectral informa- 
tion. This is added as a third dimension of values to the two-dimensional spatial image, generating a three-dimensional data cube containing any absorption, reflectance, or fluorescence spectrum data for each image pixel [19]. Hyperspectral imaging (HSI) integrates conventional imaging and spectroscopy to obtain both spatial and spectral information simultaneously from a sample at spatial resolutions varying from the level of single cells up to the macroscopic objects giving it a comparative advantage of enabling rapid and nondestructive automated screening on a large-scale [20]. Data acquired using HSI requires preprocessing to remove the noises that it usually contains. These include noise of length variation along the direction of light leading to non-linearities from the light scattering and random and scattered noise produced from the device. These noises could considerably influence the spectra and the prediction model. This makes preprocessing the data a critical step before chemometric modeling to separate important wavelength information from unnecessary redundant information contained in the data. Several spectral preprocessing methods have been explored, depending on the type and level of noise. These methods include minimum, maximum, and range normalization, multiplicative scatter correction (MSC), standard normal variate (SNV), and Savitzky-Golay (SG) 1st and 2nd derivatives methods [21]. HSI systems have been applied at paddock, plot, farm, and catchment scales to determine the type and quality of forage [22], with no information on the factory scale, as well as on heterogeneous samples like TMR and materials used in the formulation.

Consequently, in this study, we (a) investigated and determined the moisture content of different TMRs, conventional and alternative materials using the standard oven method; (b) investigated the influence of different wavelength and preprocessing methods on prediction accuracy; and (c) developed a global model for moisture content determination irrespective of the feed or feed material.

\section{Materials and Methods}

\subsection{Sample Preparation of TMR Feed and Feed Materials}

A TMR feed sample (composed of Timothy hay: 35\% DM, corn silage: $24 \%$ DM, palm-kernel expeller: 7\% DM, almond pie 7\% DM, rice bran: $9 \% \mathrm{DM}$, mushroom medium: $6 \% \mathrm{DM}$, soy sauce cake: 6\% DM, and distillers' dry grain: 6\% DM), mixed and blended by-products (composed of palm-kernel expeller: $15 \%$ DM, almond pie: $15 \% \mathrm{DM}$, corn bran: $20 \%$ DM, rice bran: $15 \%$ DM, mushroom medium: $15 \%$ DM, soy sauce cake: $15 \%$ DM and distillers' dry grain: 5\% DM) and three major by-products (Palm-kernel expeller, almond pie, and corn bran) commonly used as feed materials were acquired from a factory in Gyeongju, Republic of Korea. The samples were processed specifically to alter the moisture content in a way that created three treatments for each sample as described below:
a. Original TMR feed sample and feed materials (Figure 1A)
b. Samples with lower moisture content than the original TMR feed and feed materials (Figure 1B)
c. Samples with higher moisture content than the original TMR feed and feed materials (Figure 1C).

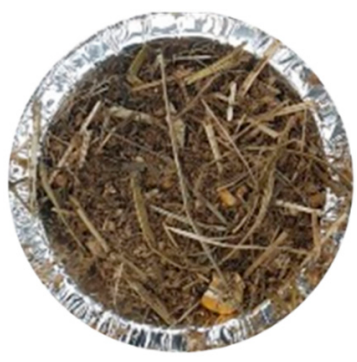

(A)

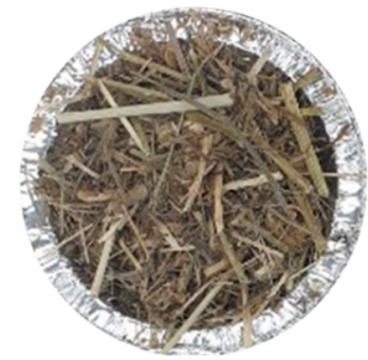

(B)

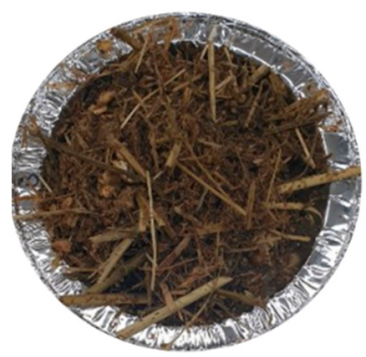

(C)

Figure 1. Images of the TMR feed: sample with original moisture content (A); sample with lower moisture content (B); and sample with higher moisture content $(\mathbf{C})$. 
To achieve this, a group of samples were kept in the original condition (one sample from each group) as shown in Figure 1A. Another group was dried at $40{ }^{\circ} \mathrm{C}$ for a total duration of $9 \mathrm{~h} 30 \mathrm{~min}$ (Figure 1B). One sample from each group was taken out of the drying oven every $30 \mathrm{~min}$ (a total of 19 samples from one group) and poured into an airtight plastic bag to achieve equilibrium moisture content. The last group was rewetted with an incremental $5 \mathrm{~mL}$ of water to $200 \mathrm{~g}$ of sample (total of 20 samples from one group), mixed thoroughly, and poured into an airtight bag to achieve equilibrium moisture (Figure 1C). These resulted in a total of 40 samples with varied moisture content for each group (TMR feed and feed materials). Equations (1) and (2) were used in computing the moisture content.

The treated samples (drying and wetting) were tempered in airtight plastic bags for $24 \mathrm{~h}$ to achieve equilibrium moisture content.

a. The initial moisture content of the samples was determined using the standard oven method $\left(135^{\circ} \mathrm{C}\right.$ for $\left.2 \mathrm{~h}\right)$ referring to Equation (1).

$$
M_{w b}=\frac{W_{m}}{W_{m}+W_{d}}
$$

where $M_{w b}$ is moisture content (MC) on wet basis (\%), $W_{m}$ is the weight of water in the feed and feed materials and $W_{d}$ is the weight of dry matter in the feed and feed materials.

b. The dry matter (DM) in the feed was computed using Equation (2).

$$
D M=W_{o} \times\left(1-M_{w b}\right)
$$

where $W_{o}$ is the initial weight of the feed and feed materials, and $M_{w b}$ is the initial moisture content of the feed and feed materials in decimal calculated using Equation (1).

The difference in weight of the wetted and dried feed and feed materials before addition of water and drying and the $D M$ (Equation (2)) were used in computing the new moisture content. The $W_{m}$ and $W_{d}$ were estimated by measuring the weight of the feed or feed materials before and after drying and wetting.

\subsection{HSI Image Acquisition of TMR Feed and Feed Materials and Correction}

The samples were prepared in a circular petri dish $(\phi 90 \times 15 \mathrm{~mm})$ with weight depending on their densities (50-100 g). The surface of the samples was evenly distributed in the petri dish before HSI acquisition.

A line-scan type short wave infrared hyperspectral imaging system was used in acquisition of the images of the samples as shown in Figure 2. The hyperspectral imaging system was made up of the following: (a) line scan type hyperspectral camera (Hyperspec SWIR, Headwall Photonics, Fitchburg, MA, USA), (b) C-mount lens with $25 \mathrm{~mm} \mathrm{f} / 1.4$ and (c) a moving stage. The camera was operated in a spectral wavelength range of 894-2504 $\mathrm{nm}$ with a spectral interval of approximately $5.85 \mathrm{~nm}$ hence a total of 275 spectral bands. A total of six $100 \mathrm{~W}$ tungsten-halogen lamps (Light Bank, Ushio Inc. Tokyo, Japan) with fiber optics (three on each side) were used to illuminate feed samples. A computer programmed motorized sample stage was integrated to move the samples towards the camera Field of View (FOV). The sensing unit was linked to a computer through a frame grabber with a standard camera link cable.

The petri dishes containing feed samples were placed onto the sample holder mounted on the translation stage. The HSI data were collected with a $47 \mathrm{~ms}$ exposure time. The distance of the sample from the camera lens was approximately $34 \mathrm{~cm}$, and the samples were measured with a scanning speed of $5.3 \mathrm{~mm} / \mathrm{s}$, and a total scan of 600 scans/sample. As the stage moved, the samples were scanned line by line in the wavelength range of $894-2504 \mathrm{~nm}$. The acquired hyperspectral images were saved in a three-dimensional format containing two spatial dimensions ( $\mathrm{x}$ and $\mathrm{y}$ ) and a spectral dimension $(\lambda)$. A total of $28 \mathrm{~s}$ was required to measure a single feed sample. 


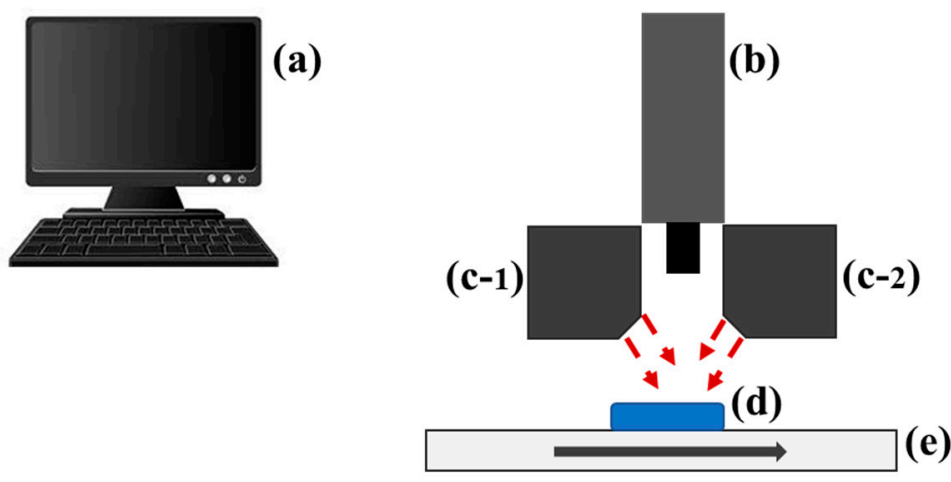

Figure 2. HSI system for spectral image acquisition from TMR feed samples: Computer unit (a); Sensing unit consisting of a lens, spectrograph, and camera (b); Light sources (c); Sample holder (d); and conveyor system (e).

\subsection{Calibration of Spectral Images}

Calibration steps were applied to remove the dark current noise and non-uniform illumination effect from the sample images using the white and dark reference images acquired during measurement. The dark image ( $0 \%$ reflectance) was obtained by turning off the light source and covering the lens with a black lid, and the white image ( $99 \%$ reflectance) was obtained with a white Teflon board. Thus, the normalized reflectance value was calculated using Equation (3).

$$
X_{C}=\frac{T_{i j}^{R}-T_{i j}^{D}}{T_{i j}^{W}-T_{i j}^{D}}
$$

where $T_{i j}^{R}(\lambda)$ is the raw reflectance image of the feed sample, $T_{i j}^{D}(\lambda)$ is the dark image, $T_{i j}^{W}(\lambda)$ is the white image, and $X_{C}$ is the calibrated image. Where $i$ and $j$ are the pixel number and waveband, respectively.

\subsection{Preprocessing of Spectral Images}

Calibrated feed sample images were preprocessed to remove background noises. This was done to acquire an image containing only the sample (Figure 3) and avoid any interference from the background [23]. For preprocessing of the image, a single waveband image was selected from the hypercube. The hyperspectral band image of $1140 \mathrm{~nm}$ was used to remove the irrelevant background pixels because of the highest peak of sample at this band. This was because the plotted spectra showed the highest peak near 1140 $\mathrm{nm}$ waveband, thus the highest difference from the background. A threshold value (0.46) was applied to turn all the sample pixels as 1 and the background pixels were turn to 0 (Figure 3). The threshold value was selected at the average value between the maximum and minimum values of the feed and feed material samples and the background pixel intensity. For perfect background removal, the final masked image was created using the morphological method (image erodes and filling) in the masked image with the primary background removed. The background free band image was then multiplied to each image in hypercube to generate a background free hypercube.

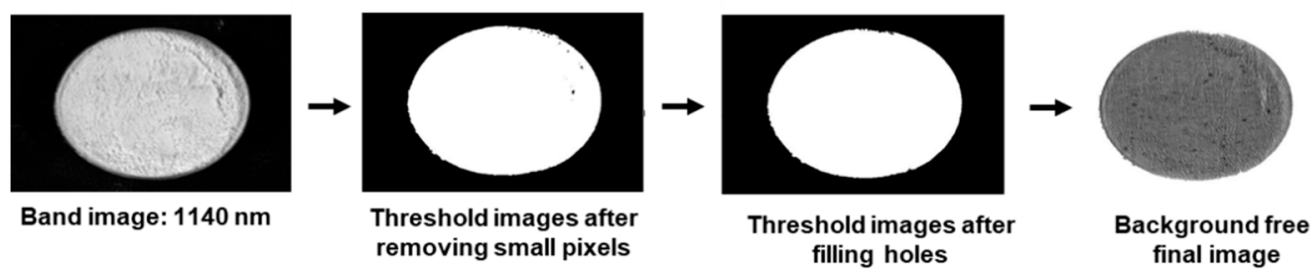

Figure 3. Preprocessing steps of hyperspectral image for discarding background area. 


\subsection{Pre-Processing of HSI Data Acquired from TMR Feed and Feed Materials}

Optimal data collection is the most important step in developing hyperspectral imaging models for the prediction of components. The acquired hyperspectral image spectrum contains numerous noises, such as random noise, the noise of length variation along the direction of light leading to non-linearities from the light scattering which could significantly influence the spectra, and scattered noise produced from the device. Preprocessing of spectral data is the most critical step before chemometric modeling using tools such as Partial Least Squares (PLS) and Principal Component Analysis (PCA). Consequently, it is necessary to preprocess spectra to separate important wavelength information from unnecessary redundant information contained in the data [24]. In this study, several spectral preprocessing methods were explored to correct HSI data. These include normalization methods (minimum, maximum, and range normalization), Standard normal variate (SNV), multiplicative scatter correction (MSC), and Savitzky-Golay (SG) 1st and 2nd derivatives methods.

\section{i. Multiplicative Scatter Correction (MSC)}

Multiplicative Scatter Correction (MSC) is a concept where undesirable scatter effect is removed from the data matrix preceding model development. Two steps are used in MSC (Equations (4) and (5)):

a. Correction coefficient estimation

$$
X_{\text {org }}=b_{o}+b_{r e f, 1} \cdot X_{r e f}+e
$$

b. Logged spectrum correction

$$
X_{\text {corr }}=\frac{X_{\text {org }}-b_{o}}{b_{r e f, 1}}=X_{r e f}+\frac{e}{b_{r e f, 1}}
$$

where $X_{\text {org }}$ is original sample spectra, $X_{\text {ref }}$ is reference spectrum, $e$ is the unmodeled part of $X_{\text {org }}, X_{\text {corr }}$ is the corrected spectra, and $b_{0}$ and $b_{r e f, 1}$ are scalar parameters.

ii. Standard Normal Variate (SNV)

Standard Normal Variate (SNV) is another method applied to scatter correction. The basic format for SNV correction is the same as that for the conventional MSC (Equation (6)).

$$
X_{\text {corr }}=\frac{X_{\text {org }}-a_{0}}{a_{1}}
$$

where $a_{0}$ is the average value of the sample spectrum to be corrected, $a_{1}$ is the standard deviation of the sample spectrum.

\section{iii. Savitzky-Golay derivations}

Savtizky and Golay (SG) popularized a method for numerical derivation of a vector that includes a smoothing step. To find the derivative at center point $i$, a polynomial is fitted in a symmetric window on the raw data. When the parameters for this polynomial are calculated, the derivative of any order of this function can easily be found analytically, and this value is subsequently used as the derivative estimate for this center point. This operation is applied to all points in the spectra sequentially. The number of points used to calculate the polynomial (window size) and the degree of the fitted polynomial are both decisions that need to be made. The highest derivative that can be determined depends on the degree of the polynomial used during the fitting (i.e., a third-order polynomial can be used to estimate up to the third-order derivative).

\subsection{Development of Moisture Content Prediction Models for TMR Feed and Feed Materials}

The preprocessed spectra were used to develop the partial least squares regression (PLSR) model. PLSR is a multivariate analysis method used to assess the correlation between various independent variables $(X)$ and dependent variables $(Y)$ [25]. Since a bad 
signal-to-noise ratio (SNR) was observed for the wavelengths above $1917 \mathrm{~nm}$, because of the sensitivity of the detector, we selected the waveband range between 894-1917 nm (175 bands) excluding the noisier spectral region. The prediction after this wavelength $(1917 \mathrm{~nm})$ is poor and not robust. Subsequently, the wavelengths that have a major influence on moisture content prediction were selected based on the beta coefficient obtained from developed PLS model. Additionally, the significant band for moisture content prediction in this study was below the $1917 \mathrm{~nm}$ bands as also reported in [26,27]. The efficiency of PLS regression model was evaluated based on the prediction accuracy $\left(R^{2}\right)$ and standard errors for calibration, cross-validation, and prediction. Inappropriate numbers of latent variables selection can cause under- or over-fitting, leading to suppression of spectral information, incorrect model interpretation, and spectral noise in the regression model. Consequently, the optimal number of latent variables was selected based on the lowest value of predicted root mean square error (RMSE) by the leave-one-out cross-validation process during the cross-validation $(\mathrm{CV})$ process.

PLS regression was implemented as multivariate analysis and regression method to determine the linear models of prediction between the spectral data (X-matrix, $\mathrm{N}_{\text {samples }} \times$ $\mathrm{K}_{\text {wavelengths }}$ ) and the values of the parameters obtained from the reference measurement $\left(\mathrm{Y}\right.$-matrix, $\left.\mathrm{N}_{\text {samples }} \times 1\right)$. The linear relationship between $\mathrm{X}$ and $\mathrm{Y}$ is predicted using Equations (7) and (8).

$$
\begin{aligned}
& X=\mathrm{TP}^{\mathrm{T}}+\mathrm{E} \\
& \mathrm{Y}=\mathrm{UQ}^{\mathrm{T}}+\mathrm{F}
\end{aligned}
$$

where $\mathrm{Y}$ is the matrix of dependent variables conforming to the sample values measured from the reference data obtained using standard oven methods and calculations in Equations (1) and (2). $\mathrm{X}$ is the $n \times \mathrm{p}$ matrix of independent variables corresponding to the spectral variables for each hyperspectral measurement. The matrix $X$ decomposes into the loading matrix $\mathrm{P}$, score matrix $\mathrm{T}$, and error matrix $\mathrm{E}$. The matrix $\mathrm{Y}$ decomposes into the loading matrix $Q$, score matrix $U$, and error matrix $F$.

Furthermore, the entire $X$ and $Y$ matrix data were divided into calibration and validation sets, which consisted of $70 \%$ of the data for calibration and $30 \%$ for validation.

\subsection{Model Evaluation of TMR Feed and Feed Materials}

The developed models were evaluated using several statistical parameters. This includes coefficient of determination shown in Equation (9). The coefficient of determination encompasses calibration $\left(R^{2} C\right)$, prediction $\left(R^{2} P\right)$, and cross-validation $\left(R^{2} C V\right)$. Other statistical parameters were the standard error of calibration (SEC), prediction (SEP), and cross-validation (SEV).

$$
R^{2}=\frac{\sum_{i=1}^{n}\left(y_{i}-\hat{Y}_{i}\right)^{2}}{\sum_{i=1}^{n}\left(y_{i}-\bar{Y}\right)^{2}}
$$

where the predicted and measured components in TMR feed and feed materials are $\hat{Y}_{i}$ and $y_{i}$, respectively. The number of validation sets observations is denoted with $n$ and the mean of measured values is denoted with $\bar{Y}$.

\subsection{Image Visualization and Moisture Content Distribution Map of Samples}

The moisture content of the TMR feed and feed materials were computed for each pixel to visualize the corresponding distribution made possible with each pixel in a hyperspectral image possessing a spectrum. Although it is practically impossible to obtain the precise quality parameters of every pixel within a sample by chemical analysis, it could be predicted by the optimal calibration model. The hyperspectral image was unfolded into a twodimensional (2D) matrix and then multiplied by the regression (beta) coefficient obtained from the best calibration model and applied to the selected wavelengths. The resultant vector was then folded back to form a $2 \mathrm{D}$ image. A median filter of $3 \times 3$ was applied to the $2 \mathrm{D}$ image for enhancing image quality for visual display. The difference in the predicted 
attributes within one sample and those from other sources can be visualized from the generated 2D images.

The steps of data preprocessing, prediction model development, and generating concentration maps are shown in Figure 4. The algorithms were implemented in MATLAB, version 2020a (MathWorks, Natick, MA, USA).

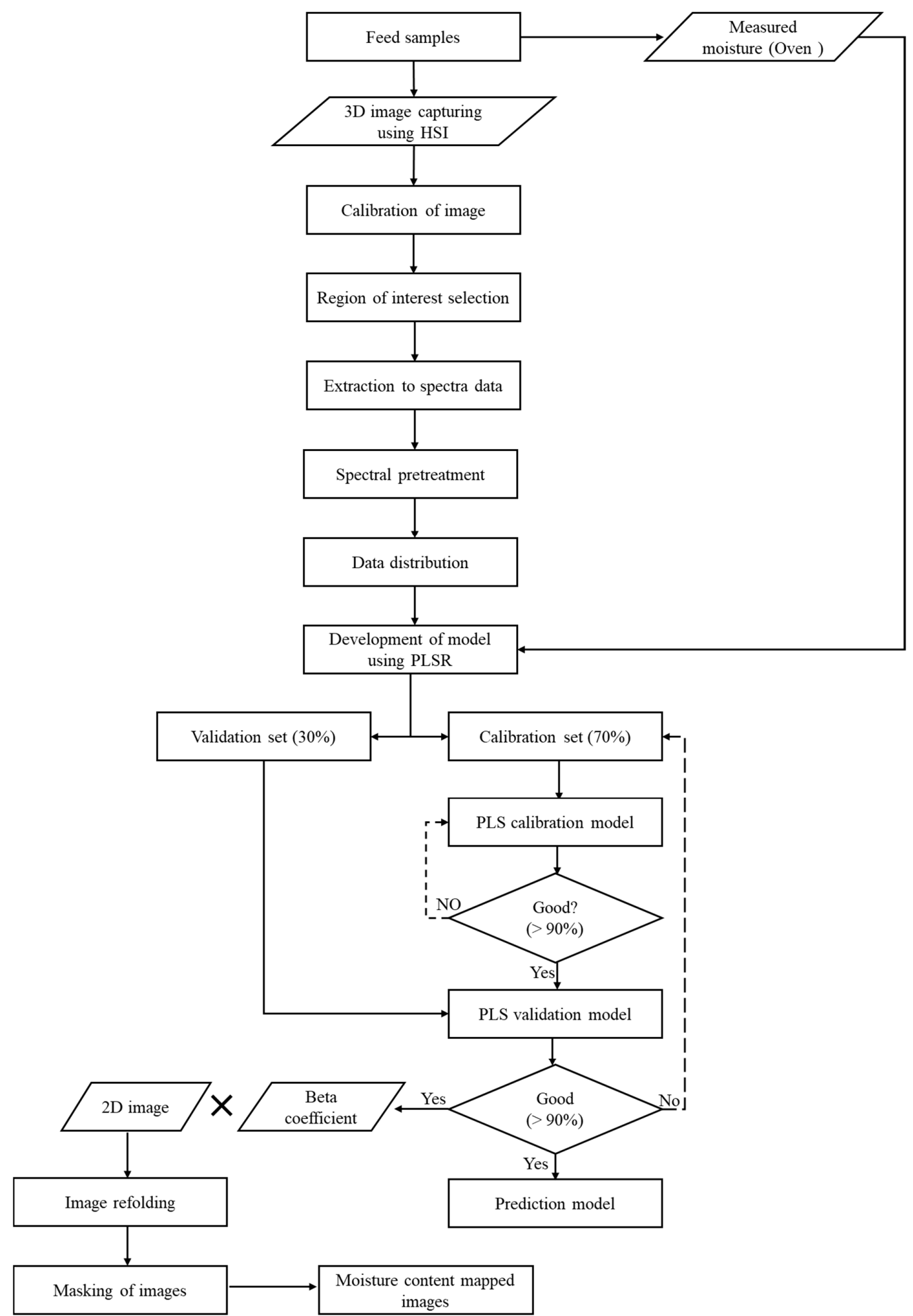

Figure 4. Steps used in processing hyperspectral images and developing moisture content prediction models regardless of the type of feed and feed materials. 


\section{Results and Discussion}

The computed moisture content with initially measured values using the oven drying method ranged from 13 to $78 \%$ for the TMR feed (S1), 5 to $54 \%$ for the mixed by-products (S2), 1.59 to $76.41 \%$ for palm kernel expeller (S3), 2.25 to $62.42 \%$ for almond pie (S4) and 4.43 to $52.21 \%$ for corn bran (S5) (Table A1 in Appendix A).

\subsection{HSI Features of TMR Feed and Feed Materials}

The MSC preprocessed spectra (Figure 6A) and mean spectra (Figure 6B) for all the samples ( $\mathrm{n}=40$ samples $\times 5$ samples) are shown in Figure 6. The spectral region $(894 \mathrm{~nm}-$ $1917 \mathrm{~nm}$ ) used is related to various peaks in broadband such as the $\mathrm{O}-\mathrm{H}, \mathrm{C}-\mathrm{H}$, and $\mathrm{N}-\mathrm{H}$ functional groups. The disparities in spectral pattern appeared particularly around 1150 $\mathrm{nm}-1250 \mathrm{~nm}$, and $1400 \mathrm{~nm}-1750 \mathrm{~nm}$. In addition, the peaks around $1225 \mathrm{~nm}$ and $1420 \mathrm{~nm}$ are associated with the $\mathrm{C}-\mathrm{H}$ and $\mathrm{O}-\mathrm{H}$ overtones, respectively. The small peak at $1530 \mathrm{~nm}$ is associated with the $\mathrm{N}-\mathrm{H}$ stretch first overtone and $1660 \mathrm{~nm}$ to the aromatic $\mathrm{C}-\mathrm{H}$ stretch first overtone [28]. These represent the variation in the moisture, carbohydrate, and protein contents of the samples [28,29].

\subsection{Prediction of Moisture Content in the Samples}

Table 1 shows the results obtained from PLSR model developed with each preprocessing method. All methods showing a good prediction accuracy $\left(R^{2}\right)$ of over $93 \%$ and prediction errors (SEP) of less than 5\%. The PLSR prediction values for moisture content in multiple by-product samples are shown in Figure 7, where most of the predicted values fall near the line of best fit.

Preprocessing methods and partial least squares regression multivariate technique and were applied to the acquired spectra. We used the spectral data in the wavelength range between $894 \mathrm{~nm}$ and $1917 \mathrm{~nm}$ to build the models as the HSI system used in this study produces noisy spectra above $1917 \mathrm{~nm}$. From the data preprocessing methods in Table 1, the range preprocessing method generated the maximum correlation coefficient values with $R^{2} C$ of $0.98, R^{2} V$ of 0.97 , and $R^{2} P$ of 0.98 . It also had the least SEP of $2.59 \%$. However, all other methods were also satisfactory, with less than $5 \%$ SEP values. The optimal number of latent variables was determined from minimum SEV values in the cross-validation process.

Table 1. Results obtained with global PLSR model for prediction of moisture content in multiple by-products.

\begin{tabular}{|c|c|c|c|c|c|c|c|c|c|}
\hline \multirow{2}{*}{ Method } & \multirow{2}{*}{$\begin{array}{c}n \text { of Calibration } \\
\text { Set }\end{array}$} & \multirow{2}{*}{$\begin{array}{c}n \text { of Validation } \\
\text { Set }\end{array}$} & \multirow{2}{*}{$\mathbf{L V}^{\mathbf{a}}$} & \multicolumn{2}{|c|}{ Calibration $^{b}$} & \multicolumn{2}{|c|}{ Cross-Validation $^{c}$} & \multicolumn{2}{|c|}{ Prediction $^{\mathrm{d}}$} \\
\hline & & & & $R^{2} C^{e}$ & $\operatorname{SEC}^{\mathrm{f}}(\%)$ & $\mathbf{R}^{2} \mathbf{V}^{\mathrm{g}}$ & SEV h $\left.^{\text {h }} \%\right)$ & $\mathbf{R}^{2} \mathbf{P}^{\mathbf{i}}$ & SEP $\mathrm{j}(\%)$ \\
\hline Mean k & 140 & 60 & 10 & 0.98 & 2.61 & 0.97 & 2.83 & 0.98 & 2.76 \\
\hline $\operatorname{Max}^{1}$ & 140 & 60 & 10 & 0.98 & 2.49 & 0.97 & 2.82 & 0.98 & 2.63 \\
\hline Range $^{m}$ & 140 & 60 & 10 & 0.98 & 2.62 & 0.97 & 2.92 & 0.98 & 2.59 \\
\hline MSC n $^{n}$ & 140 & 60 & 10 & 0.97 & 2.90 & 0.97 & 3.18 & 0.97 & 2.86 \\
\hline $\mathrm{SNV}^{\mathrm{o}}$ & 140 & 60 & 10 & 0.98 & 2.76 & 0.97 & 3.04 & 0.98 & 2.68 \\
\hline $\begin{array}{c}\text { Savitzky } \\
\text { Golay (1st) } p\end{array}$ & 140 & 60 & 10 & 0.97 & 2.99 & 0.96 & 3.47 & 0.97 & 3.31 \\
\hline $\begin{array}{c}\text { Savitzky } \\
\text { Golay (2nd) } \mathrm{q}\end{array}$ & 140 & 60 & 10 & 0.94 & 4.19 & 0.93 & 4.81 & 0.93 & 4.58 \\
\hline Raw $^{r}$ & 140 & 60 & 10 & 0.96 & 3.68 & 0.95 & 4.07 & 0.95 & 4.11 \\
\hline
\end{tabular}

${ }^{\mathrm{a}}$ LV: Latent variable; ${ }^{\mathrm{b}}$ Calibration (comparison of a known standard measured values and measurement using I); ${ }^{\mathrm{c}}$ Cross-validation (model evaluation with independent data set to test performance); ${ }^{\mathrm{d}}$ Prediction (estimation of the quantity of moisture using the developed models); ${ }^{\text {e }} \mathrm{R}^{2} \mathrm{C}$ : Coefficient of determination for calibration; ${ }^{\mathrm{f}} \mathrm{SEC}$ : standard error of calibration; ${ }^{\mathrm{g}} \mathrm{R}^{2} \mathrm{~V}$ : coefficients of determination for cross-validation; ${ }^{\text {h }}$ SEV: standard error of cross-validationI; ${ }^{i} \mathrm{R}^{2} \mathrm{P}$ : Coefficient of determination for prediction; ${ }^{j}$ SEP: standard error of prediction; Preprocessing methods ( ${ }^{\mathrm{k}}$ Mean; ${ }^{\mathrm{l}} \mathrm{Max} ;{ }^{\mathrm{m}}$ Range; ${ }^{\mathrm{n}}$ Multiplicative Scatter Correction (MSC); ${ }^{\circ}$ Standard Normal Variate (SNV) and ${ }^{\mathrm{P}}$ Savitzky-Golay 1st derivation; ${ }^{\mathrm{q}}$ Savitzky-Golay 2nd derivation) and ${ }^{\mathrm{r}}$ Raw data model (Raw). 


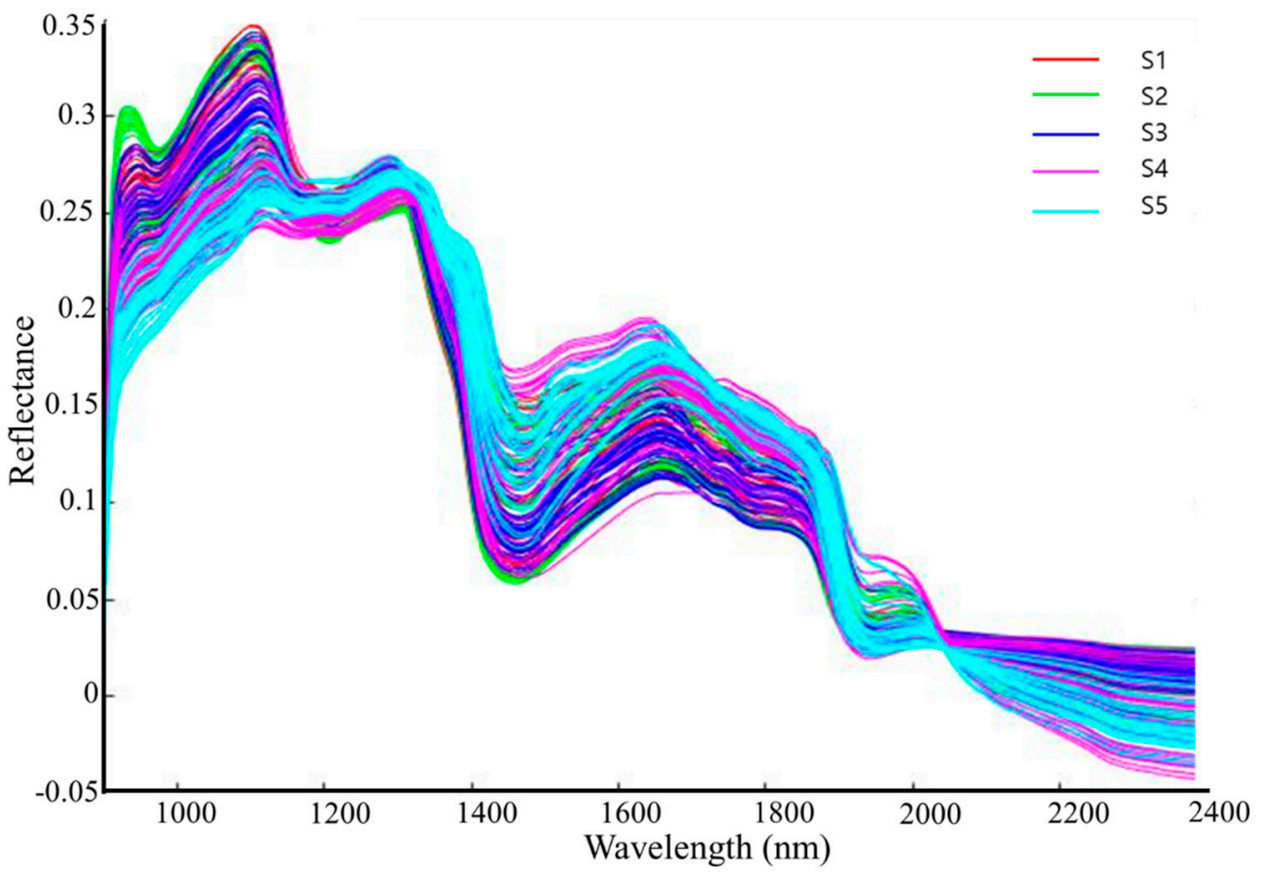

(A)

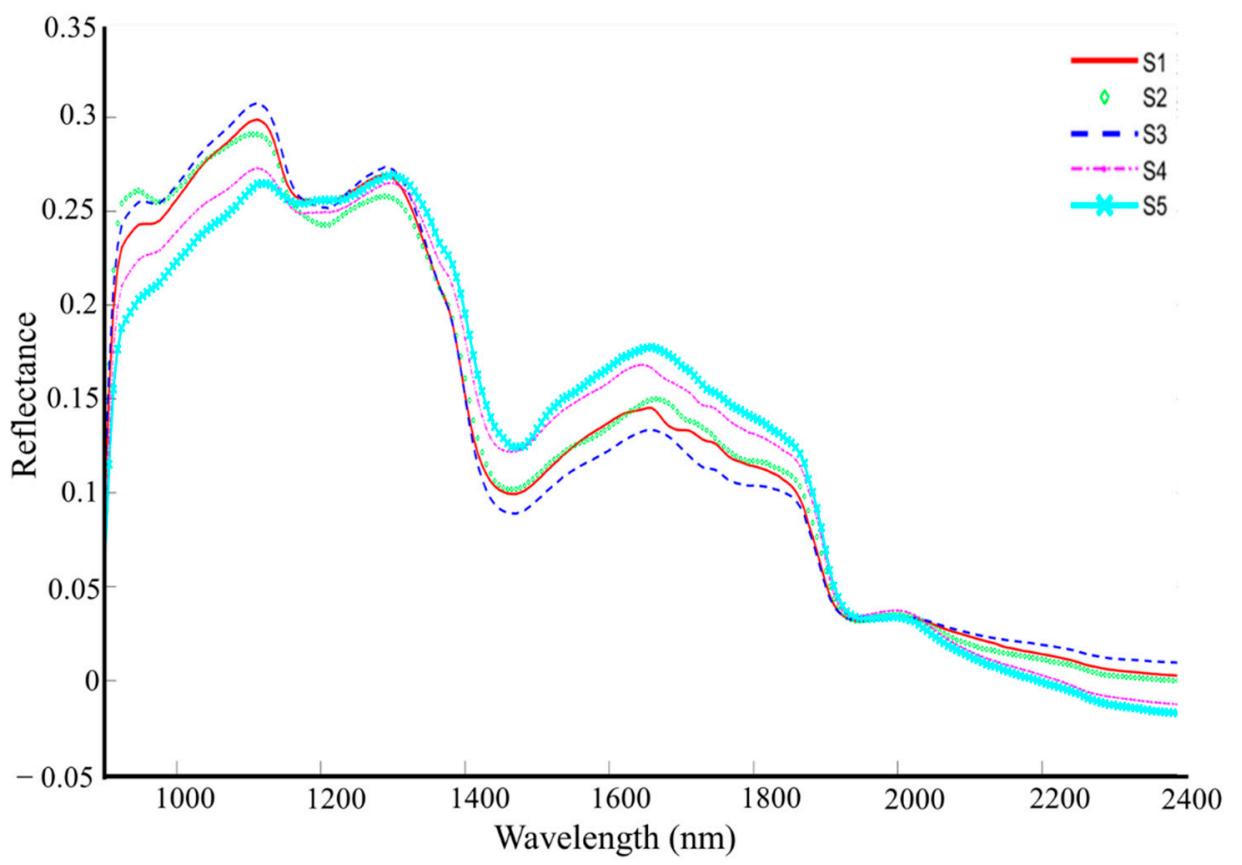

(B)

Figure 5. MSC preprocessed spectra (A) and mean spectra (B) of TMR feed and by-product samples $(n=200)$ for moisture content prediction (S1: TMR; S2: mixed by-products; S3: palm kernel expeller; S4: almond pie; S5: corn bran). 


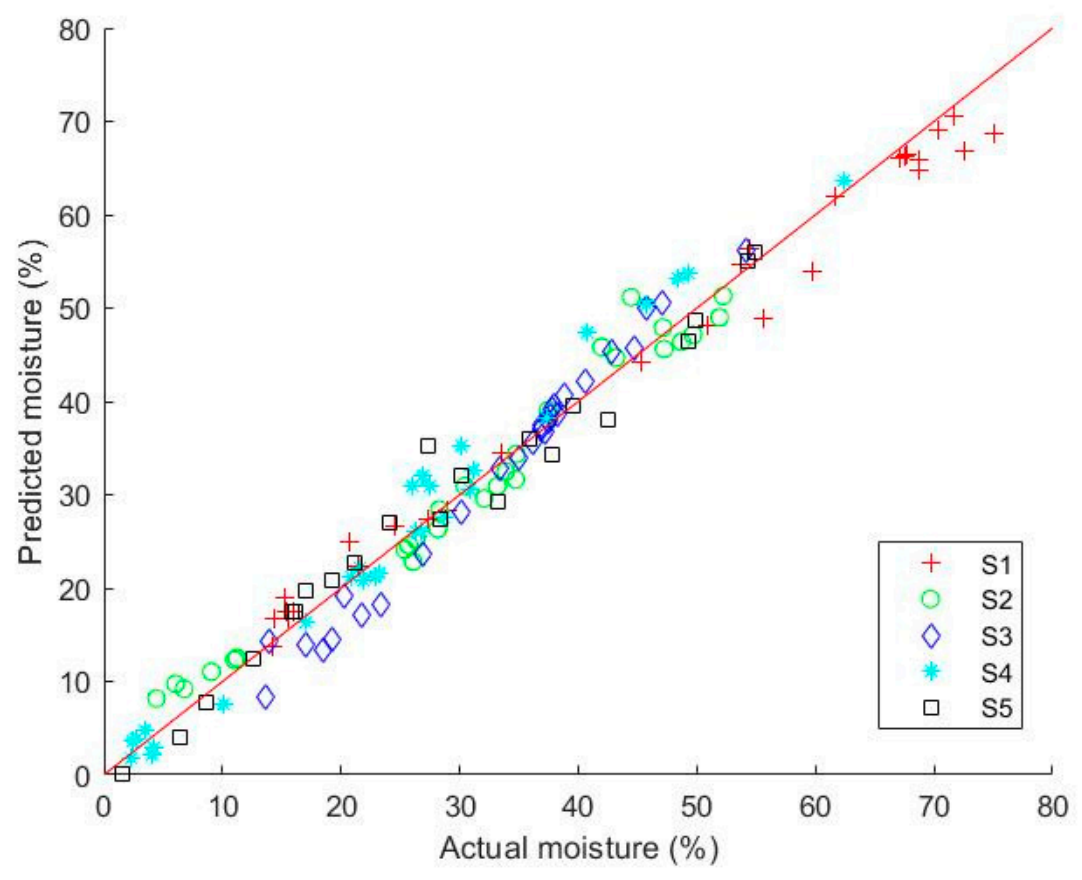

(A)

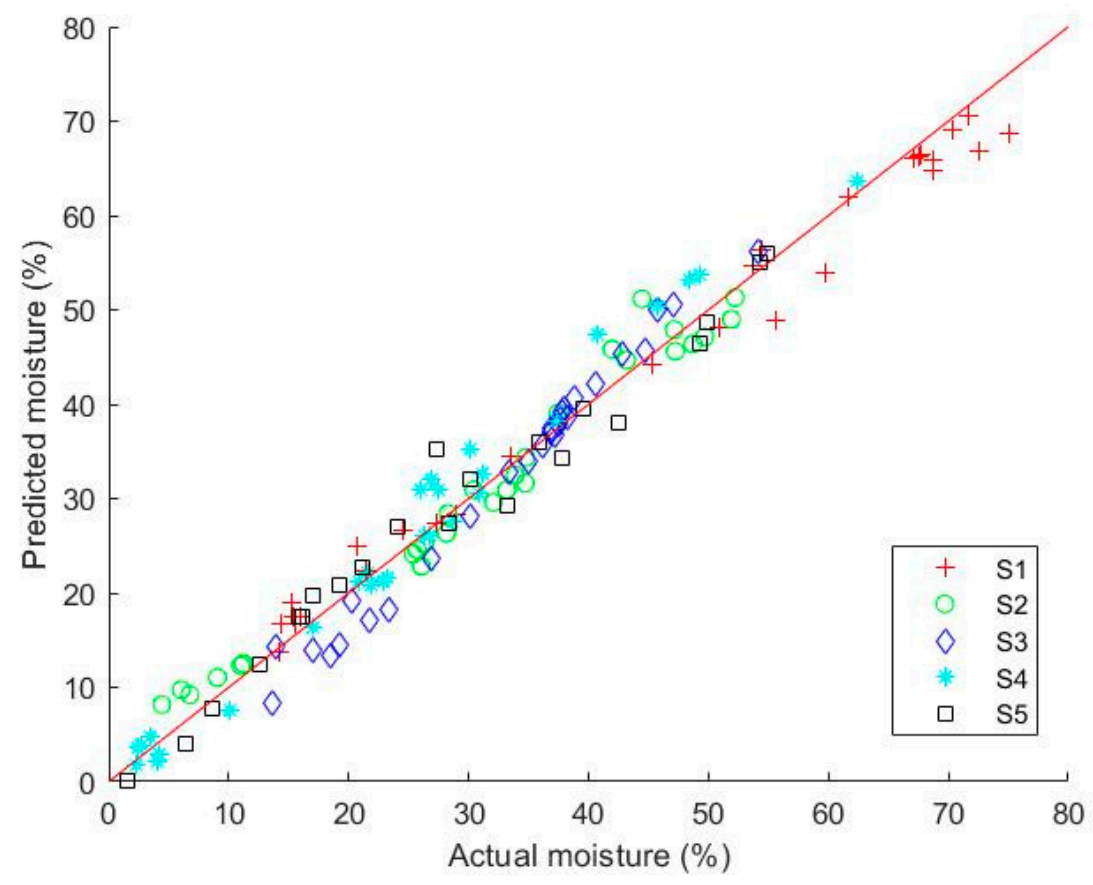

(B)

Figure 6. Moisture content prediction plot: (A) Calibration plot; (B) Prediction plot (S1: TMR; S2: mixed by-products; S3: palm kernel expeller; S4: almond pie; S5: corn bran).

Overtones and combinations of fundamental vibrations of molecules comprising - $\mathrm{OH}$, $-\mathrm{NH}$, and - $\mathrm{CH}$ groups are characterized in the near-infrared (NIR) spectrum. These would absorb based on the component such as moisture content, protein, etc. [30]. The broadband peaks in the spectrum are shown in the beta coefficient graph for all the preprocessing methods in Figure 8. In Figure 8E,F, the Savitzky Golay 1st and 2nd preprocessing methods showed that the highest positive peaks were obtained around $1660 \mathrm{~nm}$ and $1400 \mathrm{~nm}$, 
respectively. However, these were not the important peaks in the developed model. The considerable amount of other nutrients contained in the TMR feed and feed materials such as carbohydrate and protein resulted in high absorption peaks. These components also increased with the reduction in moisture content as the measured components were in percentages.

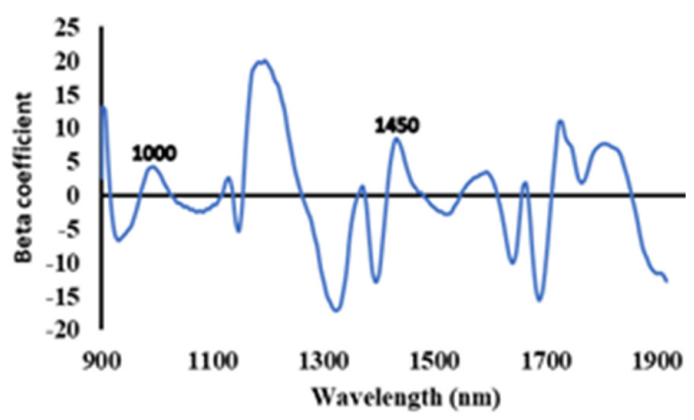

(A)

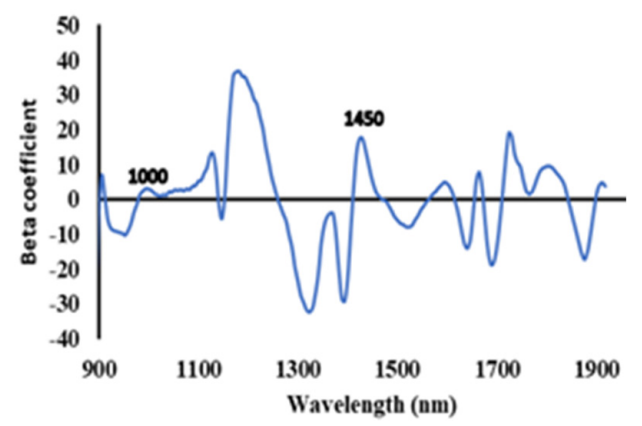

(C)

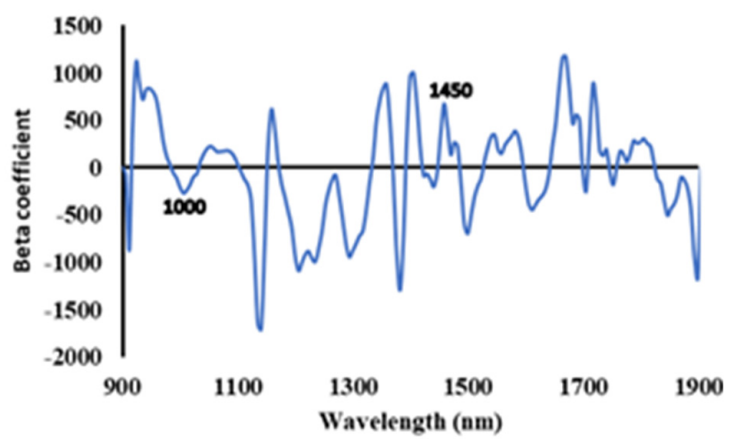

(E)

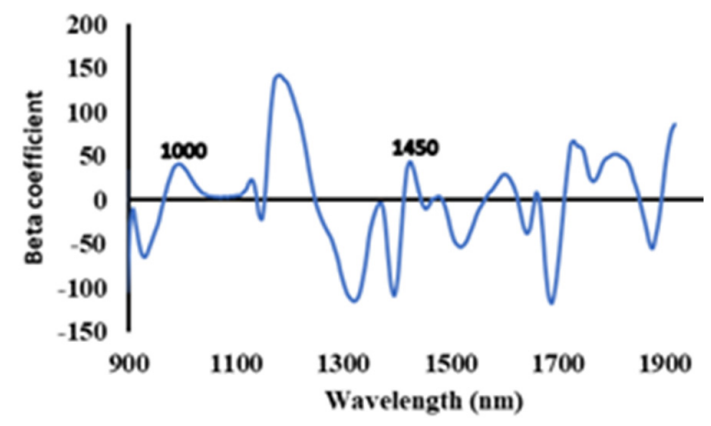

(B)

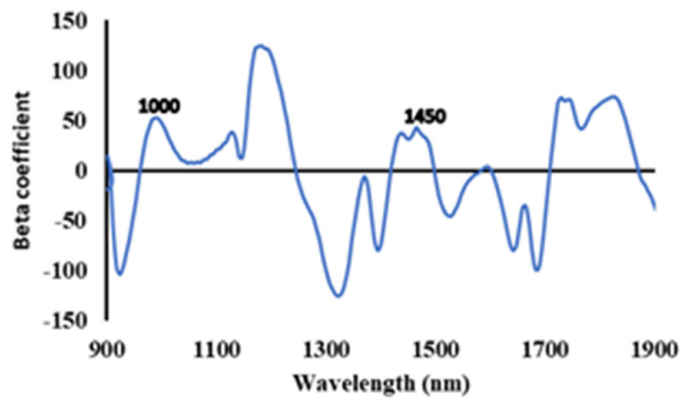

(D)

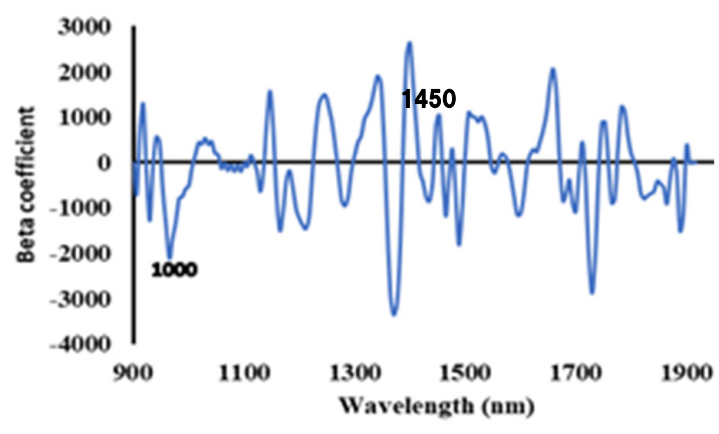

$(\mathbf{F})$

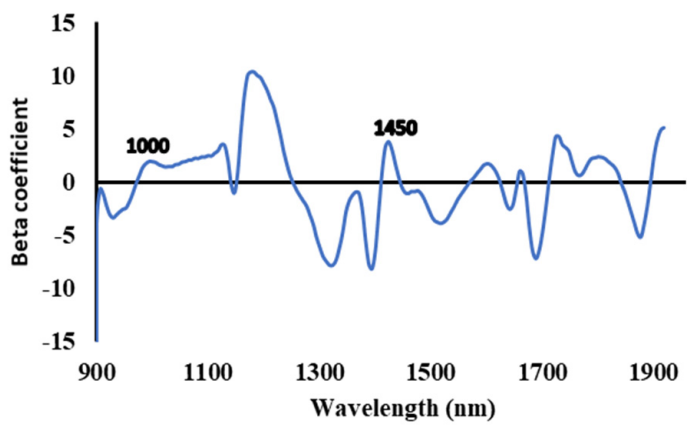

(G)

Figure 7. Beta coefficient plot: mean preprocessing (A); MSC preprocessing (B); range preprocessing (C); raw (D); Savitzky Golay 1st preprocessing (E); Savitzky Golay 2nd preprocessing (F); and SNV preprocessing (G). 
The important absorption peaks appeared around $1000 \mathrm{~nm}$ and $1450 \mathrm{~nm}$ in most of the preprocessing methods, with the exception of SNV preprocessing, where the peak at $1000 \mathrm{~nm}$ was not very conspicuous. The peak around $1000 \mathrm{~nm}$ is related to the $\mathrm{O}-\mathrm{H}$ stretching second overtone, representing the moisture content in the samples [31]. The peak at 1450 is associated with the first overtone of $\mathrm{O}-\mathrm{H}$ stretching indicating the moisture content absorption in the samples [32]. These indicate that all the models are robust and can accurately predict moisture content in the TMR feed and feed materials.

\subsection{Imaging of Moisture Content in TMR Feed and Feed Materials}

Every pixel in the hyperspectral image has its unique spectrum. As a result, the moisture content can be computed with the spectrum of any pixel in the sample. To compute the moisture content of the whole sample, all spatial pixels of the hyperspectral image should be considered. In Figure 9, the original TMR feed, SWIR hyperspectral images, and PLSR-based images for different levels of moisture content are shown. The images were developed by multiplying the obtained beta coefficient (regression coefficient) from the PLSR model with the spectra of each pixel in the image. In the generated moisture content images, the moisture content in the TMR feed was unevenly spread. The disparate colors (Figure 9) correspond to levels of moisture in the TMR feed and are proportional to the spectral differences of the individual pixels. This is because of factors such as exposure of a portion of the feed to the open environment that allows evaporation or absorption of moisture depending on the temperature and relative humidity of the storage environment and other substrates in the feed. This stops the feed from reaching an equilibrium state. These moisture maps offer rapid and easy access to the spatial distributions in which the relative intensities are indicated by the color bar. These acquired distribution maps validate the benefits of HSI in analyzing heterogeneous samples like TMR feed. This result cannot be achieved with conventional imaging or spectroscopy techniques.

Consequently, this study showed the potential of using HSI to estimate the moisture content of TMR feed and feed materials.

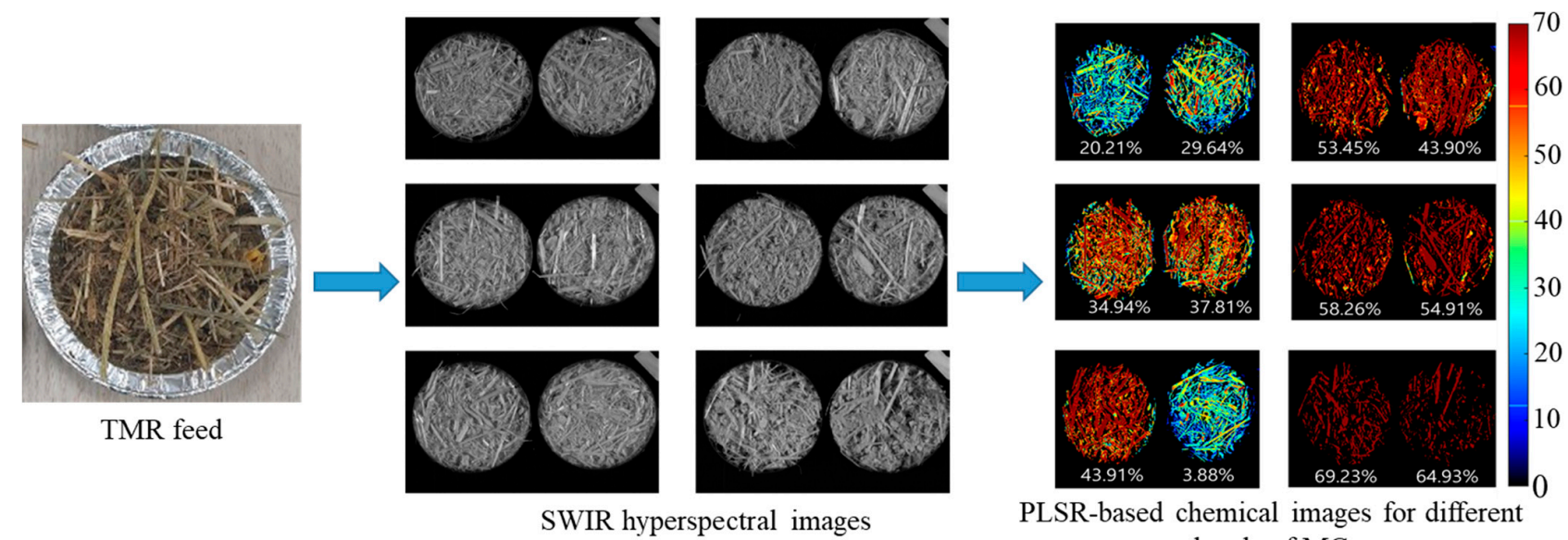
levels of MC

Figure 8. Original TMR feed, SWIR hyperspectral images of $1140 \mathrm{~nm}$, and PLSR-based images for different levels of moisture content in TMR feed.

\subsection{Models for Feed Moisture Composition Measurement}

Two models were proposed for manufacturing TMR feed with accurate moisture content. Moisture content is a very important parameter in the feed. It plays a vital role in the storability and, most significantly, the proliferation of dangerous microorganisms such as Aspergillus species that are responsible for the production of toxins such as Aflatoxin B1, as discussed in the background. Furthermore, the moisture content is inversely proportional to dry matter, which is an important component in formulating the diet of dairy cattle. The current methods to estimate the moisture content of feed and feed materials 
are destructive and time-consuming. In this research, we demonstrated the possibilities of using hyperspectral imaging technology for the rapid and non-destructive scans of all feed samples passing through the conveyor belt for safe production, storage, and feeding of livestock.

In the first proposed model (Figure 10A), since the hyperspectral imaging system is a line-scan and good for a conveyor belt system, it is installed to scan the TMR feed as it is conveyed before packaging, then storage and transportation to the farm. If the feed has an unsatisfactory moisture content, it will be diverted for retreatment using any method for water control depending on available resources and location in case of higher or lower moisture contents. The moisture content will be dependent on the class of animals being fed. After the retreatment process, the feed is re-evaluated each time until an acceptable standard is met.

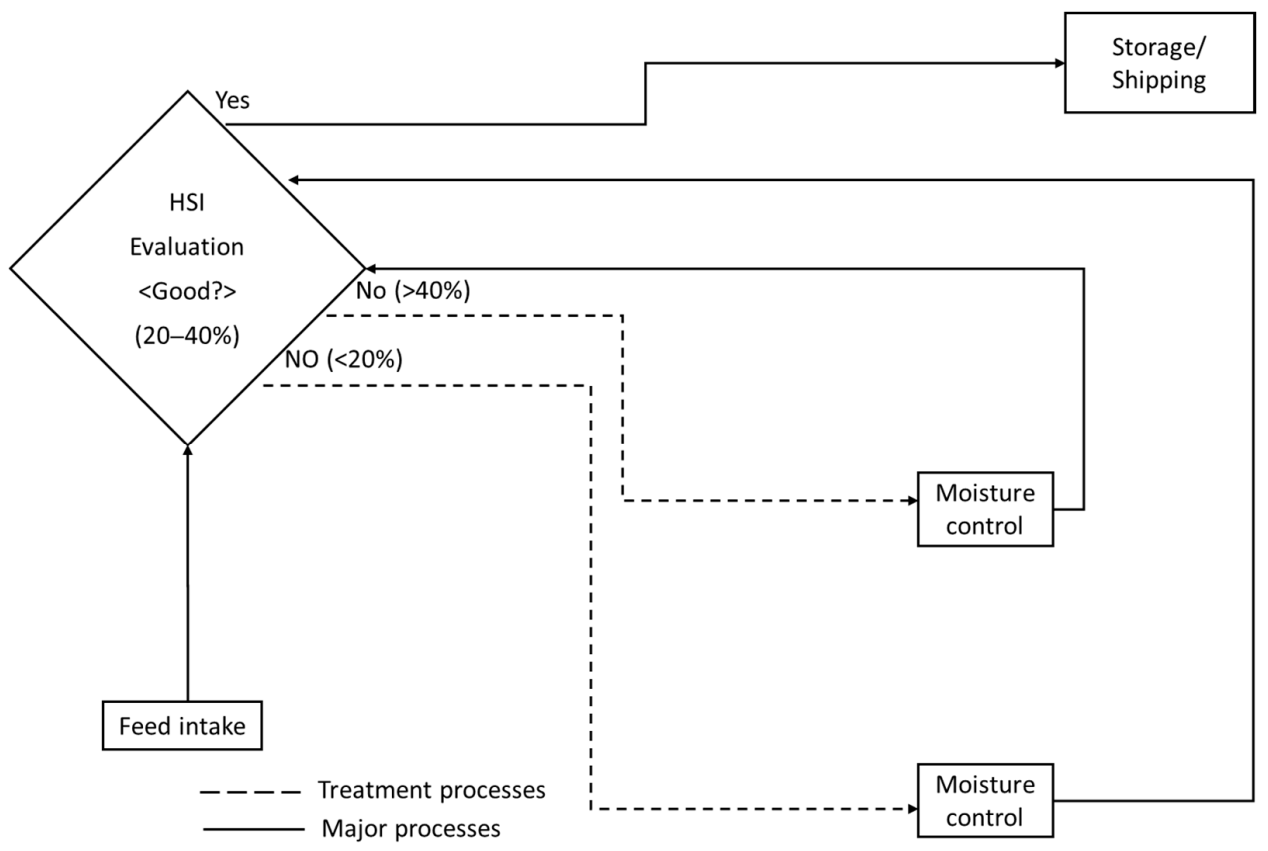

(A)

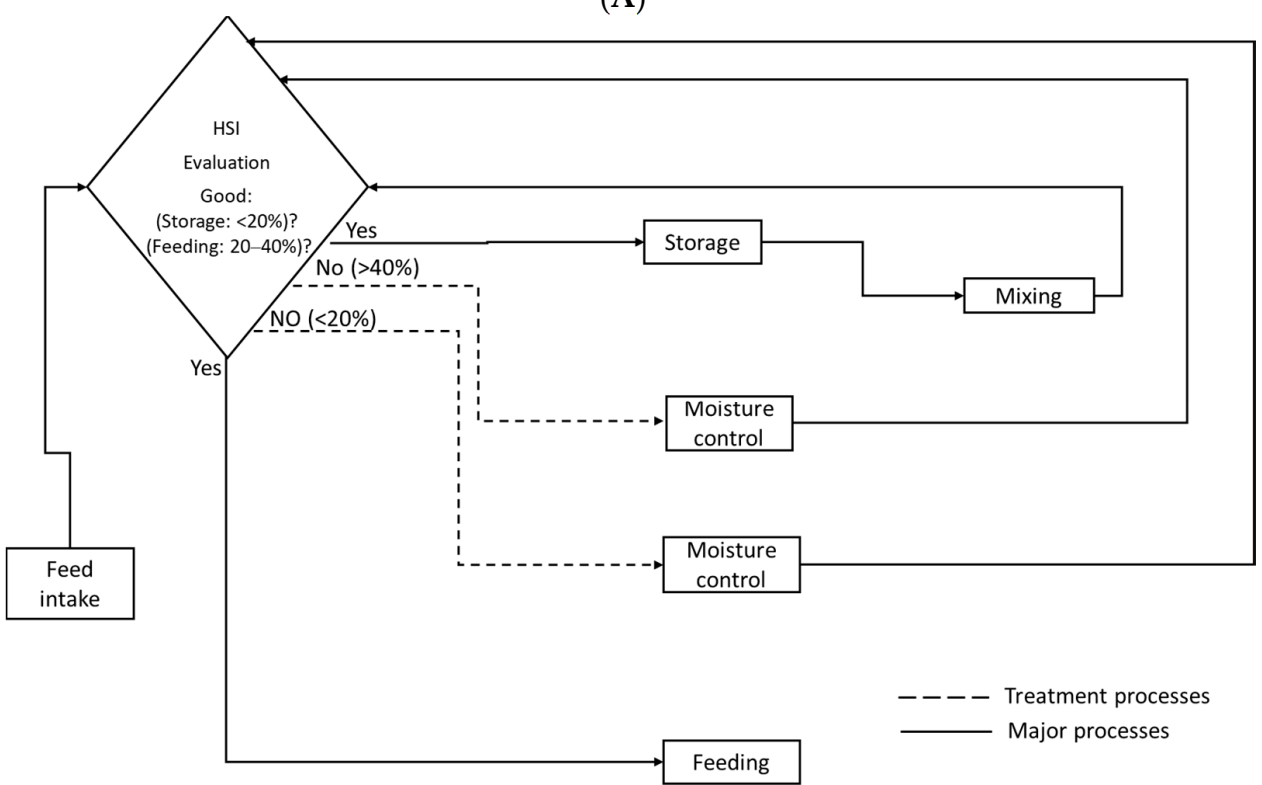

(B)

Figure 9. Model for production of TMR feed with precise moisture content and DMI in the factory (A); on the farm (B). 
In the second proposed model (Figure 10B), which is on the farm, the hyperspectral imaging system is installed to examine the feed on arrival on the farm. After line-by-line examination and dependent on the class of the animal [33] and the type of feed material or feed, a decision is made which includes for example moisture control when:

a. Moisture content greater than $40 \%$;

b. Moisture content below $20 \%$, which is specific to the feed material for storage.

In the farm situation, moisture content below $20 \%$ will be acceptable for storage since feed is most likely to be stored longer on the farm. Furthermore, mixing with by-products or roughages would be carried out after storage. The mixing can be used to balance the moisture content at this stage. However, after the mixing, if the moisture content falls below the acceptable feed standard, the TMR feed moisture must be controlled in case of more than $40 \%$ or less than $20 \%$. This process is repeated until the acceptable standard is achieved. When the moisture content is between 20 and $40 \%$, it is within the acceptable feeding range for the stage of growth of the dairy cattle considered in this study which implies no treatment is required. This is because, in the Republic of Korea, different stages of growth of dairy cattle necessitate the moisture of the feed being controlled to a set percentage.

In both models (Figure 10A,B), one hyperspectral imaging system is proposed to produce safe and satisfactory feed. Furthermore, the speed of the conveyor belt in TMR factories is within the scanning speed of the hyperspectral imaging system, suggesting it could be implemented in a commercial setting. However, high computing power would be needed to process the data in real-time.

\section{Conclusions}

A rapid and non-destructive global model that could measure the moisture content and invariably dry matter content irrespective of feed material type using a hyperspectral imaging system was proposed and developed. The developed partial least squares regression (PLSR) models using different preprocessing techniques yielded acceptable prediction accuracies $\left(\mathrm{R}^{2} \mathrm{p}\right)$ of above 0.93 and standard error of prediction (SEP) of less than $5 \%$. However, the range preprocessing technique had the best $R^{2} p(0.98)$ and SEP $(2.59 \%)$. Additionally, the visual assessment in the distribution of moisture content made possible by the generated PLSR-based moisture content mapped images could facilitate precise feed formulation. The proposed approach eliminates the extensive preparation of samples, time-consuming repetitive scans, and expertise required for conventional oven and spectroscopy procedures. Our results demonstrate that the developed model is robust, and that it could provide a method to assess the distribution of moisture in feed, while having the potential for implementation in a commercial setting. This would help prevent feed and feed material spoilage and resultant health complications, the underperformance of animals from the improper intake of dry matter, and the associated financial losses.

Author Contributions: D.D.U.: Conceptualization, Methodology, Software, Investigation, Formal analysis, Data Curation, Visualization, and Writing—original draft. J.K., S.L. \& B.-K.C.: Methodology, Investigation, Software, Data Curation, Visualization, and Writing-review \& editing. T.P. and Y.H.: Validation, Resources, Writing - review \& editing, Supervision and Funding acquisition. S.W. \& W.S.L.: Validation, Visualization, Writing-review \& editing. All authors have read and agreed to the published version of the manuscript.

Funding: This research was funded by the Basic Science Research Program through the National Research Foundation of Korea (NRF), Ministry of Education, Republic of Korea, grant number: 2018R1D1A1B07049186, and the Korea Institute of Planning and Evaluation for Technology in Food, Agriculture and Forestry (IPET) through Agriculture, Food and Rural Affairs Convergence Technologies Program for Educating Creative Global Leader, Ministry of Agriculture, Food and Rural Affairs (MAFRA), Republic of Korea, grant number: 320001-4. And the APC was funded by the National Research Foundation of Korea (NRF), Ministry of Education, Republic of Korea.

Institutional Review Board Statement: Not applicable. 
Informed Consent Statement: Not applicable.

Data Availability Statement: Not applicable.

Conflicts of Interest: All authors declare that they do not have a conflict of interest.

\section{Appendix A}

Table A1. Moisture content of TMR feed and feed materials.

\begin{tabular}{|c|c|c|c|c|c|}
\hline $\begin{array}{l}\text { Sample } \\
\text { Number }\end{array}$ & $\begin{array}{c}\text { TMR } \\
(\%)\end{array}$ & $\begin{array}{c}\text { Mixed } \\
\text { By-Products (\%) }\end{array}$ & $\begin{array}{l}\text { Palm-Kernel } \\
\text { Expeller (\%) }\end{array}$ & $\begin{array}{c}\text { Almond Pie } \\
(\%)\end{array}$ & $\begin{array}{c}\text { Corn Bran } \\
(\%)\end{array}$ \\
\hline 1 & 50.84 & 37.44 & 15.84 & 13.87 & 29.60 \\
\hline 2 & 46.26 & 36.55 & 39.57 & 17.02 & 27.30 \\
\hline 3 & 68.77 & 41.95 & 49.90 & 19.20 & 28.16 \\
\hline 4 & 67.52 & 44.70 & 20.20 & 20.33 & 26.32 \\
\hline 5 & 64.37 & 40.61 & 23.71 & 21.59 & 25.71 \\
\hline 6 & 67.05 & 37.98 & 49.23 & 22.91 & 25.38 \\
\hline 7 & 67.07 & 38.23 & 16.13 & 23.27 & 26.07 \\
\hline 8 & 75.12 & 37.16 & 42.52 & 21.85 & 47.84 \\
\hline 9 & 62.10 & 35.05 & 25.58 & 26.29 & 47.21 \\
\hline 10 & 55.69 & 33.37 & 27.34 & 26.35 & 48.70 \\
\hline 11 & 54.39 & 37.79 & 28.34 & 27.52 & 30.42 \\
\hline 12 & 61.69 & 36.12 & 33.20 & 26.69 & 28.27 \\
\hline 13 & 68.80 & 40.32 & 37.73 & 30.30 & 34.76 \\
\hline 14 & 67.65 & 39.76 & 21.14 & 31.15 & 33.88 \\
\hline 15 & 72.57 & 37.52 & 12.63 & 26.32 & 33.17 \\
\hline 16 & 71.73 & 36.91 & 20.62 & 30.93 & 34.35 \\
\hline 17 & 59.74 & 42.83 & 19.26 & 16.98 & 36.39 \\
\hline 18 & 58.29 & 48.64 & 53.22 & 18.73 & 32.08 \\
\hline 19 & 78.69 & 47.05 & 19.67 & 25.95 & 47.24 \\
\hline 20 & 70.42 & 32.93 & 9.92 & 11.28 & 14.14 \\
\hline 21 & 13.18 & 34.59 & 30.29 & 10.13 & 52.21 \\
\hline 22 & 15.43 & 37.01 & 16.97 & 5.50 & 44.45 \\
\hline 23 & 24.47 & 45.78 & 3.69 & 4.26 & 49.67 \\
\hline 24 & 25.04 & 54.99 & 54.36 & 3.41 & 48.71 \\
\hline 25 & 58.65 & 38.75 & 24.12 & 20.87 & 43.17 \\
\hline 26 & 15.19 & 36.95 & 57.99 & 37.41 & 34.72 \\
\hline 27 & 14.39 & 37.64 & 8.58 & 40.97 & 47.14 \\
\hline 28 & 14.21 & 34.18 & 63.95 & 45.75 & 49.69 \\
\hline 29 & 28.89 & 54.13 & 1.59 & 62.42 & 45.75 \\
\hline 30 & 15.49 & 49.29 & 35.82 & 49.27 & 51.90 \\
\hline 31 & 20.72 & 23.30 & 49.03 & 4.12 & 6.04 \\
\hline 32 & 52.59 & 31.26 & 76.41 & 2.25 & 4.43 \\
\hline 33 & 54.71 & 26.15 & 1.71 & 2.70 & 9.07 \\
\hline 34 & 45.31 & 30.07 & 2.97 & 2.47 & 6.76 \\
\hline 35 & 48.03 & 26.88 & 2.64 & 28.68 & 4.49 \\
\hline 36 & 53.69 & 5.96 & 24.34 & 32.77 & 4.68 \\
\hline 37 & 33.51 & 13.69 & 54.95 & 40.80 & 11.22 \\
\hline 38 & 16.02 & 18.56 & 6.34 & 48.33 & 11.02 \\
\hline 39 & 24.31 & 21.80 & 30.15 & 30.13 & 9.78 \\
\hline 40 & 21.43 & 19.27 & 4.54 & 26.96 & 12.96 \\
\hline
\end{tabular}

\section{References}

1. Park, Y.W. Moisture and water activity. Handb. Process. Meats Poult. Anal. 2008, 35-67. [CrossRef]

2. Woo, S.M.; Uyeh, D.D.; Kim, J.; Ha, Y.S. A fermentation and storage TMR model for dairy cattle. Eng. Agric. Environ. Food 2019, 12, 89-97. [CrossRef]

3. Ha, Y.-S.; Hong, D.-H.; Park, K.-K. Modeling of a small group scale TMR plant for beef cattle and dairy farm in Korea (I)Development of TMR plant model. J. Biosyst. Eng. 2009, 34, 342-350. [CrossRef]

4. Pardo, E.; Marın, S.; Sanchis, V.; Ramos, A. Prediction of fungal growth and ochratoxin A production by Aspergillus ochraceus on irradiated barley grain as influenced by temperature and water activity. Int. J. Food Microbiol. 2004, 95, 79-88. [CrossRef] 
5. Los, A.; Ziuzina, D.; Bourke, P. Current and future technologies for microbiological decontamination of cereal grains. J. Food Sci. 2018, 83, 1484-1493. [CrossRef]

6. Rezaei, F.; Vandergheynst, J.S. Critical moisture content for microbial growth in dried food-processing residues. J. Sci. Food Agric. 2010, 90, 2000-2005. [CrossRef] [PubMed]

7. Wei, X.; Su, S.; Yue, Y.; Wang, W.; He, L.; Li, H.; Ota, Y. Electric Vehicles Charging Scheduling Strategy Considering the Uncertainty of Photovoltaic Output. In Proceedings of the IOP Conference Series: Materials Science and Engineering, Shanghai, China, 24-26 March 2017; p. 012006.

8. Felton, C.; DeVries, T. Effect of water addition to a total mixed ration on feed temperature, feed intake, sorting behavior, and milk production of dairy cows. J. Dairy Sci. 2010, 93, 2651-2660. [CrossRef] [PubMed]

9. Miller-Cushon, E.; De Vries, T. Effect of dietary dry matter concentration on the sorting behavior of lactating dairy cows fed a total mixed ration. J. Dairy Sci. 2009, 92, 3292-3298. [CrossRef]

10. Ishimwe, R.; Abutaleb, K.; Ahmed, F. Applications of thermal imaging in agriculture-A review. Adv. Remote Sens. 2014, 3, 128. [CrossRef]

11. Kandala, C.V.; Butts, C.L.; Nelson, S.O. Capacitance sensor for nondestructive measurement of moisture content in nuts and grain. IEEE Trans. Instrum. Meas. 2007, 56, 1809-1813. [CrossRef]

12. Abegaonkar, M.P.; Karekar, R.; Aiyer, R. Miniaturized nondestructive microwave sensor for chickpea moisture measurement. Rev. Sci. Instrum. 1999, 70, 3145-3149. [CrossRef]

13. Ghulam, A.; Li, Z.-L.; Qin, Q.; Yimit, H.; Wang, J. Estimating crop water stress with ETM + NIR and SWIR data. Agric. For. Meteorol. 2008, 148, 1679-1695. [CrossRef]

14. Jafari, A.; Connolly, V.; Frolich, A.; Walsh, E. A note on estimation of quality parameters in perennial ryegrass by near infrared reflectance spectroscopy. Ir. J. Agric. Food Res. 2003, 42, 293-299.

15. Maertens, K.; Reyns, P.; De Baerdemaeker, J. On-line measurement of grain quality with NIR technology. Trans. ASAE 2004, 47, 1135. [CrossRef]

16. Ahn, J.; Kil, D.Y.; Kong, C.; Kim, B. Comparison of oven-drying methods for determination of moisture content in feed ingredients. Asian Australas. J. Anim. Sci. 2014, 27, 1615. [CrossRef]

17. Lohumi, S.; Lee, S.; Lee, H.; Cho, B.-K. A review of vibrational spectroscopic techniques for the detection of food authenticity and adulteration. Trends Food Sci. Technol. 2015, 46, 85-98. [CrossRef]

18. Hamblin, M.R.; Avci, P.; Gupta, G.K. Chapter 1-Introduction to Imaging in Dermatology. In Imaging in Dermatology; Hamblin, M.R., Avci, P., Gupta, G.K., Eds.; Academic Press: Boston, MA, USA, 2016; pp. 1-4. [CrossRef]

19. Rahman, A.; Faqeerzada, M.A.; Cho, B.-K. Hyperspectral imaging for predicting the allicin and soluble solid content of garlic with variable selection algorithms and chemometric models. J. Sci. Food Agric. 2018, 98, 4715-4725. [CrossRef]

20. Li, L.; Zhang, Q.; Huang, D. A review of imaging techniques for plant phenotyping. Sensors 2014, 14, 20078-20111. [CrossRef]

21. Verboven, S.; Hubert, M.; Goos, P. Robust preprocessing and model selection for spectral data. J. Chemom. 2012, 26, 282-289. [CrossRef]

22. Pullanagari, R.R.; Kereszturi, G.; Yule, I. Integrating airborne hyperspectral, topographic, and soil data for estimating pasture quality using recursive feature elimination with random forest regression. Remote Sens. 2018, 10, 1117. [CrossRef]

23. El Masry, G.; Wang, N.; Vigneault, C.; Qiao, J.; El Sayed, A. Early detection of apple bruises on different background colors using hyperspectral imaging. LWT Food Sci. Technol. 2008, 41, 337-345. [CrossRef]

24. Rinnan, Å.; Van Den Berg, F.; Engelsen, S.B. Review of the most common pre-processing techniques for near-infrared spectra. TrAC Trends Anal. Chem. 2009, 28, 1201-1222. [CrossRef]

25. Wold, M. Physical Model Study of Caving under Massive Sandstone Roof Conditions at Moura, Queensland; Division of Geomechanics, IEER: Mt. Waverley, Australia, 1984.

26. Kavdir, I.; Buyukcan, M.B.; Lu, R.; Kocabiyik, H.; Seker, M. Prediction of olive quality using FT-NIR spectroscopy in reflectance and transmittance modes. Biosyst. Eng. 2009, 103, 304-312. [CrossRef]

27. Zhou, G.X.; Ge, Z.; Dorwart, J.; Izzo, B.; Kukura, J.; Bicker, G.; Wyvratt, J. Determination and differentiation of surface and bound water in drug substances by near infrared spectroscopy. J. Pharm. Sci. 2003, 92, 1058-1065. [CrossRef] [PubMed]

28. Chen, L.; Yang, Z.; Han, L. A review on the use of near-infrared spectroscopy for analyzing feed protein materials. Appl. Spectrosc. Rev. 2013, 48, 509-522. [CrossRef]

29. Uyeh, D.D.; Ha, Y.; Park, T. Animal feed formulation: Rapid and non-destructive measurement of components from waste by-products. Anim. Feed Sci. Technol. 2021, 274, 114848. [CrossRef]

30. Workman, J.; Weyer, L. Practical Guide to Interpretive Near-Infrared Spectroscopy; CRC Press: Boca Raton, FL, USA, 2008.

31. Kandpal, L.M.; Lee, H.; Kim, M.S.; Mo, C.; Cho, B.-K. Hyperspectral reflectance imaging technique for visualization of moisture distribution in cooked chicken breast. Sensors 2013, 13, 13289-13300. [CrossRef] [PubMed]

32. Lin, L.; He, Y.; Xiao, Z.; Zhao, K.; Dong, T.; Nie, P. Rapid-detection sensor for rice grain moisture based on NIR spectroscopy. Appl. Sci. 2019, 9, 1654. [CrossRef]

33. Uyeh, D.D.; Mallipeddi, R.; Pamulapati, T.; Park, T.; Kim, J.; Woo, S.; Ha, Y. Interactive livestock feed ration optimization using evolutionary algorithms. Comput. Electron. Agric. 2018, 155, 1-11. [CrossRef] 